http://www.pakjas.com.pk

\title{
CYTOLOGICAL AND PHENOLOGICAL CHARACTERIZATION OF ADAPTED GENETIC STOCKS DERIVED FROM Triticum aestivum/ Thinopyrum bessarabicum
}

\author{
Anber Hamdani' ${ }^{1}$, Alvina Gul ${ }^{2}$, Hadi Bux ${ }^{3, *}$, Sadaf Tabasum Qureshi ${ }^{3}$ and Abdul Mujeeb-Kazi ${ }^{4,5}$ \\ ${ }^{1}$ Department of Plant Breeding and Genetics, PMAS Arid Agriculture University, Rawalpindi, Pakistan; ${ }^{2}$ Atta-ur- \\ Rahman School of Applied Biosciences, National University of Sciences and Technology (NUST), Islamabad, \\ Pakistan; ${ }^{3}$ Institute of Plant Sciences, University of Sindh Jamshoro, Pakistan; ${ }^{4}$ Department of Botany, \\ University of Sargodha, Sargodha, Pakistan; ${ }^{5}$ Texas A\&M University, Texas, USA. \\ "Corresponding author's e-mail: hadiqau@gmail.com
}

\begin{abstract}
The diploid maritime grass Thinopyrum bessarabicum $\left(2 \mathrm{n}=2 \mathrm{x}=14, \mathrm{E}^{\mathrm{b}} \mathrm{E}^{\mathrm{b}}\right)$ hybridized with bread wheat (Triticum aestivum $\mathrm{L}$., $2 n=6 x=42, A A B B D D)$ yielding a self-sterile $F_{1}$ intergeneric hybrid $\left(2 n=4 x=28, A B D E^{b}\right)$. By back or top crossing, the hybrid with bread wheat cultivars, individual disomic Th. bessarabicum chromosome addition lines were produced with 44 chromosomes $\left(2 \mathrm{n}=6 \mathrm{x}=42+2=44 ; \mathrm{AABBDD}+1 \mathrm{E}^{\mathrm{b}} 1 \mathrm{E}^{\mathrm{b}}\right.$ to $\left.7 \mathrm{E}^{\mathrm{b}} 7 \mathrm{E}^{\mathrm{b}}\right)$. Also, earlier produced by using $\mathrm{F}_{1}$ hybrid clones were the colchicine induced amphiploids $\left(2 \mathrm{n}=8 \mathrm{x}=56\right.$; $\left.\mathrm{AABBDDE} \mathrm{E}^{\mathrm{b}} \mathrm{E}^{\mathrm{b}}\right)$. These genetic stocks were produced and maintained by the wide cross program at National agriculture research center (NARC) and studied cytologically and phenologically. The disomic chromosome additions are a conduit towards providing information on trait associations with grass chromosomes after stress screening, followed by cytogenetic manipulations to effect subtle alien chromatin transfers into homoeologous chromosomes of wheat. Each addition line was stable at 44 chromosomes, possessed regular bivalent meiosis and high fertility. The amphiploid was also cytologically normal. Phenological details permitted some additions to be readily characterized as follows: tapering spike $=$ group $2 \mathrm{E}^{\mathrm{b}} 2 \mathrm{E}^{\mathrm{b}}$, solid stem $=$ group $3 \mathrm{E}^{\mathrm{b}} \mathrm{E}^{\mathrm{b}}$, blue aleurone seed $=$ group $4 \mathrm{E}^{\mathrm{b}} \mathrm{E}^{\mathrm{b}}$ and club shaped spike $=$ group 5 $\mathrm{E}^{\mathrm{b}} \mathrm{E}^{\mathrm{b}}$. The seed repository in Pakistan is the wide cross program in NARC, Islamabad.
\end{abstract}

Keywords: Wheat, karyotyping, intergeneric hybridization, Triticeae gene pool, disomic addition lines, amphiploidy, stress tolerance

\section{INTRODUCTION}

Bread wheat has been clearly recognized as the conduit for food security looking at the approximately 9.2 billion populaces that will inhabit this planet in 2050 (Bruinsma, 2009). An estimated 300 million tons of wheat will be required for food needs (Mujeeb-Kazi et al., 2017) and hence time bound swift impacts in wheat production are paramount. Innovative approaches that permit access and utilization of new genetic diversity do exist (Kosina and Heslop-Harrison, 1996) but so far has been sparsely utilized (Mujeeb-Kazi et al., 2013) to elevate the current yield tends per hectare via intraspecific, interspecific and intergeneric hybridization. There are various options that can harness the genetic diversity of the wild species and relatives of the Triticeae gene pools (Jiang et al., 1995) with priority usage of the alien resources being on those wheat species combinations in which chromosome associations permit spontaneous alien gene transfers. Thus, the tertiary gene pool arsenal lacking desired level of homoeologous associations, is the last step of the ladder to be used in gene transfer programs but nevertheless possess genetic diversity whose introgession protocols are very challenging.
Use of diploids in the tertiary gene pool for complex trait improvements like salinity or drought had a distinct advantage and attached preference to Th. bessarabicum and L. elongatum (Mujeeb-Kazi, 2006). Th. bessarabicum was selected as a potent runner for hybridization and it was independently hybridized by Mujeeb-Kazi et al. (1983) and Gorham et al. (1986). The latter independently also produced an amphiploid and attached value to practical crop cultivation traits needed to combat various biotic and abiotic stresses (Gorham et al., 1986; Xu et al., 2004; Zhang et al., 2005). Focusing on salt tolerance, the amphiploid of wheat and $T h$. bessarabicum $(2 \mathrm{n}=8 \mathrm{x}=56$; $\mathrm{AABBDDEbEb})$ has applied agricultural potential with its high salt tolerance (MujeebKazi et al., 1996), capable of withstanding up to $350 \mathrm{~mol} \mathrm{ml}^{-}$ ${ }^{3}$ of $\mathrm{NaCl}$ (King et al., 1996). Chromosome 5J $\left(\mathrm{E}^{b}\right)$ of $T h$. bessarabicum has a major role in salt tolerance (Colmer et al., 2006) with the contribution of chromosomes 4 and 7 also reported as being positive (Mujeeb-Kazi et al., 1993, Gul, 2011).

Therefore, the salinity tolerance contribution of chromosomes from Th. bessarabicum is concerned when another diploid ( $L$. elongatum) has chromosomes of groups 3,4 and 7 to be positive contributors. These three chromosomes have also 
been shown to be involved for Th. bessarabicum, contradictory to the exclusive role of chromosome $5 \mathrm{~J}\left(\mathrm{E}^{b}\right)$ (Forster et al., 1987, 1988); a discrepancy that requires stringent future evaluation. Hence adequate seed amounts are needed that are well documented cytologically and phenologically. As Pakistan has excellent field sites for trials therefore documentation characterized for multi-locational trials should validate the association, leading to the necessity of this study.

\section{MATERIALS AND METHODS}

Germplasm and growing seedlings: Seed of cultivar Chinese Spring (CS), the intergeneric amphiploid of bread wheat with Th. Bessarabicum and its seven addition lines in the Wide Cross and Cytogenetics Program at NARC, Islamabad, Pakistan (Table 1) were germinated in petri dishes. Individual seedlings were transplanted in Jiffy-7 Peat Pellets. After 10 days of growth, the seedlings of amphiploid, the 7 disomic addition lines were transplanted into pots filled with a soil mix comprised of soil:sand:leaf manure $(2: 1: 1)$ and placed in an open screen house. The addition lines $\left(1 \mathrm{E}^{\mathrm{b}}, 2 \mathrm{E}^{\mathrm{b}}, 3 \mathrm{E}^{\mathrm{b}}, 4 \mathrm{E}^{\mathrm{b}}, 5 \mathrm{E}^{\mathrm{b}}\right.$, $6 \mathrm{E}^{\mathrm{b}}$ and $7 \mathrm{E}^{\mathrm{b}}$ ) were also planted (Hill Plantation) in the field at NARC, for a random increase for initial usage in field trials.

Cytological characterization: Classical cytological protocols of mitosis and meiosis (Mujeeb-Kazi et al., 1994) were used for validating the above genetic stocks. Plants with 56 chromosome and addition lines with 44 chromosomes were cytologically identified by mitosis and further validated by Giemsa C-banding using the protocol of Jahan et al. (1990) and Mujeeb-Kazi et al. (1994). All germplasm categories were meiotically analyzed to study the mean chromosome pairing relations coupled with Giemsa C-banding documentation and phenological characterization.

Table 1. Chromosomal status of wheat germplasm with parentage.

\begin{tabular}{llll}
\hline Sr. & Germplasm & Parentage $)$ & $\begin{array}{l}\text { Chromosome } \\
\text { constitution }\end{array}$ \\
\hline 1 & CS & Chinese Spring & $42(\mathrm{ABD})$ \\
2 & Amphiploid & CS/Th.bess & $56\left(\mathrm{AABBDDE}^{\mathrm{b}} \mathrm{E}^{\mathrm{b}}\right)$ \\
3 & Addition line & CS/Th.bess.//Gen 81 & $42+1 \mathrm{E}^{\mathrm{b}} 1 \mathrm{E}^{\mathrm{b}}$ \\
4 & Addition line & CS/Th.bess.//CS & $42+2 \mathrm{E}^{\mathrm{b}} 2 \mathrm{E}^{\mathrm{b}}$ \\
5 & Addition line & CS/Th.bess.//2*Gen 81 & $42+3 \mathrm{E}^{\mathrm{b}} 3 \mathrm{E}^{\mathrm{b}}$ \\
6 & Addition line & CS/Th.bess.//2*Gen 81 & $42+4 \mathrm{E}^{\mathrm{b}} 4 \mathrm{E}^{\mathrm{b}}$ \\
7 & Addition line & CS/Th.bess.//2*Gen 81 & $42+5 \mathrm{E}^{\mathrm{b}} 5 \mathrm{E}^{\mathrm{b}}$ \\
8 & Addition line & CS/Th.bess.//2*Gen 81 & $42+6 \mathrm{E}^{\mathrm{b}} 6 \mathrm{E}^{\mathrm{b}}$ \\
9 & Addition line & CS/Th.bess.//2*Gen 81 & $42+7 \mathrm{E}^{\mathrm{b}} 7 \mathrm{E}^{\mathrm{b}}$ \\
\hline
\end{tabular}

Phenological characterization: Data were recorded for days to heading, days to physiological maturity, plant height at maturity $(\mathrm{cm})$, tillers per plant, spike length $(\mathrm{cm})$, number of grains per spike and plant, 1000 grain weight, grain color and awn color.

\section{RESULTS AND DISCUSSION}

Cytological characterization: Regarding, the somatic count of the amphiploid, its seven disomic chromosome addition lines was focused on selecting plants with 56 and 44 chromosomes. Satellites were present on the short arms of three homologous chromosomes i.e. 1B, 6B and 5D (Mujeeb_Kazi and Miranda, 1985). These were observed in all the studied stocks. The secondary constriction of the 5D chromosomes though quite minute was observed in all preparations but not in all cells analyzed like earlier findings of Jahan et al. (1990) and Mujeeb-Kazi et al. (1994). They can be observed more frequently by reducing the pretreatment time (Mujeeb-Kazi and Miranda, 1985) of the root tips being processed for somatic cytology.

All disomic addition lines had a high frequency of cells with 44 chromosomes (the expected number) but hypo- and hyperploid plants were present (41 or 43) with occasional euploid plants also (42). Plants with 44 and 43 chromosomes were selected for maintenance. The C-banded karyotype distinctly identified individual $T h$. bessarabicum chromosomes and distinguished them from those of $T$. aestivum (William and Mujeeb-Kazi, 1993). In this study, also in each of the seven addition lines, 2 of the 44 chromosomes were of Th. bessarabicum whereas in the amphiploid 14 of the 56 chromosomes were alien.

The chromosomes $1 \mathrm{E}^{\mathrm{b}}, 2 \mathrm{E}^{\mathrm{b}}$ had satellites on their short arms. The chromosomes $1 \mathrm{E}^{\mathrm{b}}, 3 \mathrm{E}^{\mathrm{b}}$ and $6 \mathrm{E}^{\mathrm{b}}$ had terminal bands on both long and short arms. Terminal banding sites on short arms were observed on chromosome $2 \mathrm{E}^{\mathrm{b}}$ and $5 \mathrm{E}^{\mathrm{b}}$. The chromosome $4 \mathrm{E}^{\mathrm{b}}$ and $7 \mathrm{E}^{\mathrm{b}}$ showed terminal bands on long arms and variable terminal sites on short arms. The banding details of Th. bessarabicum chromosomes observed in the current study were similar to those reported earlier by William and Mujeeb-Kazi (1993).

Although the somatic evidence was adequate to validate the germplasm status (Table 1), meiotic data is vital for accurate elucidation of wheat chromosome associations and essential to advance wide cross programs towards practicality (Mujeeb-Kazi and Kimber, 1985). The chromosome pairing analysis in hybrids is based on the scoring of meiotic configurations i.e., uni-valents, rod and ring bivalents, trivalents and other multi-valents in metaphase- 1 meiocytes. All the disomic addition lines expressed 22 total bivalents. Meiotic studies of the above germplasm categories of materials were conducted and visualized (Table 2).

Meiotic analysis of the amphiploidy seedlings showed a regular meiotic behavior. No multivalent or unpaired chromosomes were observed in their respective meiocytes. The result of meiotic analysis is presented in Table 2. The amphiploids showed the expected 28 bivalents; variable rods and rings, but predominantly ring bivalents. The disomic addition lines provided evidence of normalcy of meiotic metaphase- 1 chromosomal associations with 22 bivalents as 
expected with normal $22+22$ anaphase 1 separation. No multivalent configurations and unpaired chromosomes were observed as reflected through the high frequency of ring bivalents. The mean chiasmata frequency per cell in addition lines ranged 49-56 per cell.

Table 2. Mean values of meiocytes studied for metaphase1 chromosome associations in genetic stocks derived from Thinopyrum bessarabicum.

\begin{tabular}{lccccc}
\hline Sample & \multirow{2}{*}{ Univalent } & \multicolumn{2}{c}{ Bivalents } & Trivalent & $\begin{array}{c}\text { Chiasmata } \\
\text { per cell }\end{array}$ \\
\cline { 3 - 4 } & & Rings & Rods & & 56.6 \\
\hline CS & - & 18.20 & 2.80 & - & 64.1 \\
Amphiploid & & 21.89 & 6.12 & & 56.9 \\
$1 E^{b}$ & - & 18.84 & 3.15 & - & 51.3 \\
$2 E^{b}$ & - & 17.30 & 4.70 & - & 49.7 \\
$3 E^{b}$ & - & 18.26 & 3.74 & - & 53.9 \\
$4 E^{b}$ & - & 20.18 & 1.89 & - & 52.5 \\
$5 E^{b}$ & - & 19.67 & 2.34 & - & 51.2 \\
$6 E^{b}$ & - & 18.84 & 3.17 & - & 55.6 \\
$7 E^{b}$ & - & 19.11 & 2.88 & - & \\
\hline
\end{tabular}

Somatic evaluation aids in discerning the hypo/hyperploid status, hence, cytological observation of each seed of the derived germplasm is essential in order to maintain normal euploid status. The conducted somatic counts have enabled substantial purification of the genetic stocks to give a wide array of plants with 56 chromosomes (amphiploid), 44 (disomic addition lines) and 43 chromosome monosomic additions that will be the back-up for future usage in case, its own progeny needs more plants with 44 chromosomal number. The seed from 43 monosomic plants will have derivatives that are 42,43 and 44 chromosomes. The unique C-banding patterns of Th. bessarabicum chromosomes have further served as diagnostic markers to detect their presence or absence. The regular meiotic behavior translates the stable transmission of the alien chromosomes to the progenies and high fertility which is beneficial for meeting the applied agricultural gains. Traditionally, alien introgressions in wheat have been characterized through meiotic M-1 pairing (Lukaszewski et al., 2005). Normalcy suggests germplasm stability that is of prime importance for stock maintenance and subsequent stress screening plus utilization. The cytological data gathered from our investigations have aided this crucial need to have sufficient seed of all genetic stocks that are well validated as done here.

Phenological characterization: The amphiploid stock showed very late heading as compared to the disomic addition lines. Days to physiological maturity in addition lines ranged from 104 to 116 days. The addition line $6 \mathrm{E}^{\mathrm{b}}$ was early maturing while $7 \mathrm{E}^{\mathrm{b}}$ showed late maturity. Plant height in case of addition lines ranged from $55-82 \mathrm{~cm}$ with $3 \mathrm{E}^{\mathrm{b}}$ being the tallest. $3 \mathrm{E}^{\mathrm{b}}$ and group 4 addition lines were taller than the amphiploidy. The amphiploid stock and $6 \mathrm{E}^{\mathrm{b}}$ addition line in general showed poor growth in the pots in the screen house. Tillering in addition lines ranged from 7 to 14 . The maximum number of tillers were for the $2 \mathrm{E}^{\mathrm{b}}$ addition line and minimum for $3 \mathrm{E}^{\mathrm{b}}$.

In $\mathrm{CS}$ and the amphiploid stock spike length ranged from 9 to $13 \mathrm{~cm}$ whereas in addition lines it ranged from 6 to $13 \mathrm{~cm}$. Maximum spike length was observed in $3 \mathrm{E}^{\mathrm{b}}$ addition line. Seed set in addition lines ranged from 17 to 41 grains per spike. Maximum seed set (41) was observed in $1 \mathrm{E}^{\mathrm{b}}$ addition line and minimum (17) was in $6 \mathrm{E}^{\mathrm{b}}$ that had the maximum number of grains per spikelet of 4 . The amphiploidy stock and $6 \mathrm{E}^{\mathrm{b}}$ addition line showed poor reproductive growth. All other disomic addition lines showed high fertility (excluding $6 \mathrm{E}^{\mathrm{b}}$ ) where seed setting ranged from 100 to 427 per plant. Maximum grains per plant were produced by $5 \mathrm{E}^{\mathrm{b}}(427)$ and minimum (100) by the $7 \mathrm{E}^{\mathrm{b}}$ addition line. Number of grains for $6 \mathrm{E}^{\mathrm{b}}$ was 35 .

In the given set of germplasm, 1000 grain weight ranged from $17 \mathrm{~g}$ to $34 \mathrm{~g}$. Maximum grain weight was shown by chromosome addition line $7 \mathrm{E}^{\mathrm{b}}$ and least by the chromosome $2 \mathrm{E}^{\mathrm{b}}$ addition line. The germplasm grain color was light to dark brown and reddish except for the group 4 addition line that possessed bluish color of the aleurone. The addition of $3 \mathrm{E}^{\mathrm{b}}$ chromosome of Th. bessarabicum in CS was found to be awnless. The CS is also an awn-less variety. The amphiploid, and $1 \mathrm{E}^{\mathrm{b}}, 2 \mathrm{E}^{\mathrm{b}}, 5 \mathrm{E}^{\mathrm{b}}$ and $6 \mathrm{E}^{\mathrm{b}}$ addition lines showed the presence of

Table 3. Phenological descriptor of genetic stocks derived from Thinopyrum bessarabicum.

\begin{tabular}{lccrrrrrrlll}
\hline Sample & DH & DPM & \multicolumn{1}{c}{ PH } & \multicolumn{1}{c}{ T/P } & \multicolumn{1}{c}{ S.L } & G/S & G/P & 1000GW & G.C & A.C & Awn \\
\hline Chinese spring & 123 & 174 & 120.0 & - & 10.2 & 67 & 315 & 24.4 & B & - & Awnless \\
Amphiploid & 134 & 163 & 70.7 & 6 & 13.2 & 19 & 32 & - & LB & CW & Awnlets \\
Translocation stock & 136 & 170 & 62.6 & 4 & 8.8 & 15 & 65 & - & LB & CW & Awnlets \\
$1 \mathrm{E}^{\mathrm{b}}$ & 79 & 110 & 67.0 & 12 & 11.2 & 41 & 384 & 19.5 & B & CW & Awnlets \\
$2 \mathrm{E}^{\mathrm{b}}$ & 78 & 110 & 70.2 & 14 & 10.6 & 35 & 316 & 17.3 & LB & CW & Awnlets \\
$3 \mathrm{E}^{\mathrm{b}}$ & 79 & 113 & 81.5 & 7 & 13.0 & 35 & 304 & 24.8 & LB & - & Awnless \\
$4 \mathrm{E}^{\mathrm{b}}$ & 80 & 113 & 77.7 & 10 & 12.7 & 26 & 305 & 22.8 & BB & CW & Awns \\
$5 \mathrm{E}^{\mathrm{b}}$ & 78 & 109 & 57.5 & 11 & 9.9 & 33 & 427 & 23.4 & LB & CW & Awnlets \\
$6 \mathrm{E}^{\mathrm{b}}$ & 80 & 104 & 55.0 & 2 & 6.9 & 17 & 35 & - & LB & CW & Awnlets \\
$7 \mathrm{E}^{\mathrm{b}}$ & 80 & 116 & 57.7 & 10 & 11.2 & 37 & 100 & 33.4 & B & CW & Awns \\
\hline
\end{tabular}

GW: 1000-Kernel weight (g); DH: Days to heading; DPM: Days to physiological maturity; T/P: No. of productive tillers per plant; SL: Spike length (cm); PH: Plant height $(\mathrm{cm}) ;$ G/S: No. of grains/spike; G/P: No. of grains per plant; GC: grain color $(B B=$ blackish brown, $\mathrm{LB}=$ light brown, $\mathrm{B}=$ brown $) ; \mathrm{AC}$ : Awn color $(\mathrm{CW}=$ Creamy white $)$ 
awn-less. The $4 \mathrm{E}^{\mathrm{b}}$ and $7 \mathrm{E}^{\mathrm{b}}$ addition line of Th. bessarabicum showed long awns resembling normal wheat. The awn type variability arose from the use of an awned bread wheat when the backcrossing (cv. Genaro 81) was done on the CS/Th. bessarabicum combination. In these derivatives, the satellite presence was different as observed where plants that had only the 6B6B and 5D5D satellites. In these plants, instead of the 1B1B chromosomes, present were two wheat/rye translocated chromosomes i.e. T1BL.1RS, T1BL.1RS which are characteristic of the $\mathrm{cv}$. Genaro 81 and the secondary constriction on the $1 \mathrm{RS}$ arms are masked.

The vegetative morphology of the amphiploid resembled Chinese Spring as to lateness, tall plants and drooping leaves with spike morphology being intermediate between the wheat parent and the grass. This is the most common observation for most intergeneric hybrids within Triticeae (Mujeeb-Kazi et al., 2008; Gorham et al., 1986) and is considered as a valid morphological indicator of alien genetic expressivity in a wheat back-ground (Mujeeb-Kazi et al., 1987, 1989). Seed setting in the amphiploid stock was poor and a small number of seed were produced that were adequate to carry out the intergeneric combinations progressive studies for achieving the practical targets focused on exploiting attributes of alien species.

In disomic addition lines the phenology of wheat parent dominates. The disomic addition lines except for group 6 exhibited good agronomic plant phenology because of the different backcross wheat parent. Several of the additions could be phenologically identified with tapering spikes linked with group 2, solid stem with group 3, blue aleurone with group 4 and club shaped spikes with group 5 as earlier reported by William and Mujeeb-Kazi (1993), and also subsequently observed by Kazi (2011) under Pakistan conditions. Additional validation protocols permit complete addition line set identification that include efficient molecular diagnostics, biochemical assays and interline crossing as well coupled with precision cytogenetics for confirmation of stability. Despite the variable seed set within the addition lines, enormous amount of seed has been produced (Table 2) for extended screening usage over several field locations and pre-breeding utilization. Integrated validation procedures used in the development and purification of the alien Th. bessarabicum genetic stocks has been a significant strategy that has enhanced research efficiency.

Phenological observations are significant for use of alien stocks in wheat improvement goals particularly for the tertiary gene pool species that lack homoeologous pairing causing transfer realization to be complex. Varieties released from any breeding program require an adequate fitness to the cropping conditions and thus using a few traits mentioned here like habit, height, maturity and yield components their potential in selecting from wide cross advanced pre-bread progenies can be deduced. This could imply that usage of the tertiary gene pool species may fall on the back burner but that does not take away its importance. There are always exceptions to generalities. It behooves us to conclude optimistically that diversity is crucial for wheat improvement and when alien sources are genomically distant from the wheat genome, one must exercise caution that stringent phenology is estimated precisely.

Alien addition lines are pivotal to pursue applied targets of agriculture, and they will become the hub of genetic manipulation protocols that will allow alien chromatin introgression into the wheat crop. Recent literature has made a wide coverage of the strategies involved (Mujeeb-Kazi et al., 2013; Ogbonnaya et al., 2013).

Th. bessarabicum is associated with resistance and tolerance against to stem rust race UG99, Fusarium head scab and salt tolerance. In order to link any trait to a chromosome/s, it is essential first that the amphiploid if available be positive for the trait/s and then from it, a complete set of addition lines are produced for screening of the trait by increasing up to certain limit. After the addition line/s get trait associated then the homoeologous exchange protocols for trait positive addition lines falls in place to give the practical resistant or tolerant effect that is desired in euploid $(2 n=6 x=42)$ derivatives.

Focusing on salt tolerance, the amphiploid of wheat and $T h$. bessarabicum $\left(2 \mathrm{n}=8 \mathrm{x}=56 ; \mathrm{AABBDDE}^{\mathrm{b}} \mathrm{E}^{\mathrm{b}}\right)$ has applied agricultural potential with its high salt tolerance (MujeebKazi et al., 1996) capable of withstanding up to $350 \mathrm{~mol} \mathrm{ml}^{-3}$ of $\mathrm{NaCl}$ (King et al., 1996). Chromosome 5J ( $\left.\mathrm{E}^{\mathrm{b}}\right)$ of Th. bessarabicum has played a major role in salt tolerance (Colmer et al., 2006) with the contribution of chromosomes 4 and 7 also reported as being positive (Mujeeb-Kazi et al., 1993). Thus, there does exist a concern regarding the salinity tolerance contribution of chromosomes from $T h$. bessarabicum.

In a related diploid Lophopyrum elonagtum groups 3, 4 and 7 were earlier reported to be positive contributors and the same have been shown to be involved according to Mujeeb-Kazi et al., (1996) for Th. bessarabicum, contradictory to the exclusive role of chromosome 5J ( $\mathrm{E}^{\mathrm{b}}$ ) (Forster et al., 1987, and 1988); a variation which requires stringent future valuation.

Table 4. Basic statistics for eight quantitative traits under study.

\begin{tabular}{llcc}
\hline S. No. & Traits & Mean & Range \\
\hline 1 & Days to Heading & $94.7 \pm 25.3$ & $78-136$ \\
2 & Days to Maturity & $128.2 \pm 28.5$ & $104-174$ \\
3 & Plant Height (cm) & $72.0 \pm 19.0$ & $55-120$ \\
4 & Tillers per Plant & $8.5 \pm 3.90$ & $2-14$ \\
5 & Spike Length (cm) & $10.8 \pm 2.00$ & $6.9-13.2$ \\
6 & Grains per Spike & $32.5 \pm 15.2$ & $17-67$ \\
7 & Grains per Plant & $228.3 \pm 152.6$ & $32-427$ \\
8 & 1000 GW (g) & $23.7 \pm 5.1$ & $17.3-33.4$ \\
\hline
\end{tabular}


Now in our environment, we are optimistic that stringent screening under in vitro and in vivo conditions can be conducted in 7 disomic addition lines and the desire to deliver a salt tolerant derivative carrying introgression/s seems a distinct possibility that will specifically exploit innovative phph gene involvement (Mujeeb-Kazi 2006, Mujeeb-Kazi et al., 2013) for cytogenetic manipulation. This study has characterized well the germplasm and ample seed quantities are produced to permit such laboratory and field studies soon to meet the applied target of combating salinity.

Conclusion: A wide range of hybridization programs had emerged globally as wheat improvement programs to check the access of germplasm possessing allelic diversity. The genetic stocks that emerge from initial hybridization efforts if they are to be successful in applied agriculture then will require their free distribution globally and follow the conventional protocols of adaptation, seed increase, characterization, utilization and varietal release. This study has demonstrated that a distant diploid grass has been used to generate stocks that have been distributed in such a way that the recipients have validated the stocks, increased the seed characterization, and thus have been assimilated by all needy researchers under present environmental conditions. The disomic addition lines and the amphiploidy allow us to apply innovative techniques that will promote specific trait linkages to addition lines and then facilitate the production of homologous translocations preferably of the fully compensating kind. The seed of these stocks is maintained in NARC, Pakistan, North Dakota (Steven $\mathrm{Xu}$ ), and the wide cross program in CIMMYT Mexico from whom small samples up to 10 seed per stock can be freely obtained that endorses the spirit of germplasm sharing in the public domain.

\section{REFERENCES}

Colmer, T.D., T.J. Flower and R. Munns. 2006. Use of wild relatives to improve salt tolerance in wheat. J. Exp. Bot. 57:1059-1078.

Forster, B.P., J. Gorham and T.E. Miller. 1987. Salt tolerance of an amphiploid between Triticum aestivum and Agropyrum junceum. Pl. Breed. 98:1-8.

Forster, B.P., T.E. Miller and C.N. Law. 1988. Salt tolerance of two wheat Agropyron junceum disomic addition lines. Genome 30:559-564.

Gorham, J., B.P. Forster, E. Budrewicz, R.G. Wyn-Jones, T.E. Miller and C.N. Law. 1986. Salt tolerance in the Triticeae: solute accumulation and distribution in an amphiploid in an amphiploid derived from Triticum aestivum cv. Chinese Spring and Thinopyrum bessarabicum. J. Exp. Bot. 37:1114-1128.

Jahan, Q., N. Ter-Kuile, N. Hashmi, M. Aslam, A.A. Vahidy and A. Mujeeb-Kazi. 1990. The status of 1B/1R translocation chromosome in some released varieties of Pakistan. Pak. J. Bot. 22:1-10.

Jiang, J., B. Friebe and B.S. Gill. 1994. Recent advances in alien gene transfer in wheat. Euphytica 73:199-212.

Gul, A. 2011. Utilization of Triticeae gene pool diversity for wheat improvement. Ph.D. diss., Quaid-i-Azam University, Islamabad, Pakistan; pp.1-240.

King, I.P., S.E. Orford, K.A. Cant, S.M. Reader and T.E. Miller. 1996. An assessment of the salt tolerance of wheat/Thinopyrum bessarabicum $5 \mathrm{E}^{\mathrm{b}}$ addition and substitution lines. Pl. Breed. 115:77-78.

Kosina, R. and J.S. Heslop-Harrison. 1996. Molecular cytogenetics of an amphiploid trigeneric hybrid between Triticum durum, Thinopyrum distichum and Lophopyrum elongatum. Ann. Bot. 78:583-589.

Lukaszweski, A.J., B. Lapinski and K. Rybka. 2005. Limitations of in situ hybridization with total genomic DNA in routine screening for alien introgressions in wheat. Cytogenet. Gen. Res. 109:373-377.

Mujeeb-Kazi, A. 2006. Utilization of Genetic Resources for Bread Wheat Improvement. In: R.J. Singh and P.P. Jauhar (eds.), Cereals Vol II CRC Series. pp.61-97.

Mujeeb-Kazi, A. and G. Kimber. 1985. The production, cytology and practicality of wide hybrids in the Triticeae. Cereal Res. Comm. 13:111-124.

Mujeeb-Kazi, A. and J.L. Miranda. 1985. Enhanced resolution of somatic chromosome constrictions as an aid to identify intergeneric hybrids among some Triticeae. Cytologia 50:701-709.

Mujeeb-Kazi, A., S. Roldan and J.L. Miranda. 1983. Production and cytology of hybrids of Triticum aestivum L. varieties with several Agroyron and Elymus species. Agronomy Abstracts, American Society of Agronomy, p.74.

Mujeeb-Kazi, A., S. Roldan, D.Y. Suh, L.A. Sitch and S. Farooq. 1987. Production and cytogenetic analysis of hybrids between Triticum aestivum and some caespitose Agropyron species. Genome 29:537-553.

Mujeeb-Kazi, A., S. Roldan, D.Y. Suh, N. Ter-Kuile and S. Farooq. 1989. Production and cytogenetics of Triticum aestivum L. hybrids with some rhizomatous Agropyron species. Theor. Appl. Genet. 77:162-168.

Mujeeb-Kazi, A., J. Gorham and J. Lopez-Cesati. 1993. Use of wild Triticeae relatives for stress tolerance. In:International Crop Science I, D.R. Buxton, R. Shibles, R.A. Forsberg, B.L. Blad, K.H. Asay, G.M. Paulsen and R.F. Wilson (eds.), Ames, Iowa, pp.549-554.

Mujeeb-Kazi, A., Q. Jahan and A.A. Vahidy. 1994. Applications of a somatic and meiotic cytological technique to diverse plant genera and species in the Triticeae. Pak. J. Bot. 26:353-366.

Mujeeb-Kazi, A., M.N. Islam-Afridi and A. Cortes. 1996. Genome identification in some wheat and alien Triticeae 
species intergeneric hybrid by fluorescent in situ hybridization. Cytol. 61:307-315.

Mujeeb-Kazi, A., A. Cortes, A. Gul, M. Farooq, F. Majeed, I. Ahmad, H. Bux, M. William, V. Rosas and R. Delgado. 2008. Production and cytogenetics of a new Thinopyrum elongatum/Tritcum aestivum hybrid, its amphiploid and backcross derivatives. Pak. J. Bot. 40:565-579.

Mujeeb-Kazi, A., A.G. Kazi, I. Dundas, A. Rasheed, F. Ogbonnaya, P. Chen, M. Kishi, D. Bonnett, R.R.C. Wang, S. Xu, H. Bux, T. Mahmood and S. Farrakh. 2013. Genetic diversity for wheat improvement as a conduit for food security. Adv. Agron. 122:179-259.

Mujeeb-Kazi, A., N. Ali, M. Jamil, A. Ali, A. Ibrahim, A. Ghafoor, R. Delgado, J.L.D. de Leon and S. Rajaram. 2017. Tissue culture mediated allelic diversification and genomic enrichment of wheat to combat production constraints and address food security. Plant Tissue Culture and Biotechnology, June 2017 entire issue (In Press).
Ogbonnaya, F.C., O. Abdalla, A. Mujeeb-Kazi, A.G. Kazi, S. $\mathrm{Xu}$, N. Gosman, E.S. Lagudah, D. Bonnett and M.E. Sorrells. 2013. Synthetic hexaploid in wheat improvement. In: J. Janick (ed.), Plant Breeding Reviews. Vol 37 pp.35-122.

William, M.D.H.M. and A. Mujeeb-Kazi. 1993. Thinopyrum bessarabicum biochemical and cytological markers for the detection of genetic introgression in its hybrid derivatives with Triticum aestivum L. Theor. Appl. Genet. 86:365-370.

Xu, S.S., T.L. Friesen and A. Mujeeb-Kazi. 2004. Seedling resistance to tan spot and Stagonospora nodorum blotch in synthetic hexaploid wheats. Crop Sci. 44:2238-2245.

Zhang, P., S. Dreisigacker, A.E. Melchinger, J.C. Reif, A. Mujeeb-Kazi, M. Van Ginkel, D. Hoisington and M.L. Warburton. 2005. Quantifying novel sequence variation and selective advantage in synthetic hexaploid wheats and their backcross-derived lines using SSR markers. Mol. Breed. 15:1-10. 